\title{
Phenol content and antioxidant activity of green, yellow and black tea leaves
}

\author{
Mirela Kopjar ${ }^{*}$, Maja Tadić and Vlasta Piližota
}

\begin{abstract}
Background: Green, black and yellow tea leaves are rich in phenolic compounds that are known for their antioxidant activity thus beneficial effect on human health. In practice, different methods are used to determine antioxidant activity. The objective of this study was to determine content of phenols, flavonoids and tannins, as well as antioxidant activity of tea leaves.

Results: Green, yellow and black tea leaves (intact and pulverised leaves) were used for extraction by methanol or acidified methanol. Spectrophotometric methods were used for determination of selected parameters. Antioxidant activity was determined in extracts and pulverised tea leaves by application of 2,2-diphenyl-1-picrilhydrazyl (DPPH) and 2,2'azinobis-(3-ethylbenzthiazoline-6-sulphonic acid (ABTS) free radicals. For determination of antioxidant activity of the pulverised leaves, 'QUENCHER' method was used. The method is based on the direct treatment of dry sample with free radicals. Extracts obtained by extraction of pulverised tea leaves with acidified methanol had the highest phenolic content $(3.823,4.226$ and $6.829 \mathrm{~g} / \mathrm{kg}$ for green, black and yellow tea, respectively). In methanol extracts, phenol content decreased in order yellow > green > black tea and, in acidified methanol extracts, yellow > black > green tea, regardless of particle size of tea leaves for extraction. Flavonoid and tannin contents followed the same tendency as phenol content. The highest antioxidant activity had acidified methanol extracts of pulverised tea leaves, regardless of used method (DPPH and ABTS). Results of antioxidant activity obtained with 'QUENCHER' method were compared with results of acidified methanol extracts. Green and yellow tea had higher antioxidant activity when 'QUENCHER' method was used in contrast to the black tea where higher antioxidant activity was determined in extract.

Conclusions: Particle size and extraction solvent had high influence on total phenolic compounds, total flavonoid and tannin content as well as on antioxidant activity. Also, antioxidant activity of samples highly depended on used free radicals and sample preparation prior their application.
\end{abstract}

Keywords: Green; Yellow and black tea leaves; Phenol content; Antioxidant activity; DPPH; ABTS; QUENCHER method

\section{Background}

In the last decades, lots of epidemiological studies were focused on bioactive phytochemicals such as phenolic compounds due to their beneficial effect on human health. It has been suggested that an initial cause of most chronic diseases is free radical attack on biomolecules; thus, consumption of foods rich in phenolic compounds that are capable of the scavenging of reactive species may be a mechanism of protection recommending those foods for maximum health benefits. A lot of different procedures

* Correspondence: mirela.kopjar@ptfos.hr

Faculty of Food Technology Osijek, Josip Juraj Strossmayer University of Osijek, Franje Kuhača 20, 31000 Osijek, Croatia have been developed to test the total antioxidant activity of foodstuffs $[1,2]$. On the basis of different studies, it is evident that applied method and extraction of antioxidant compounds were the main issues for antioxidant activity determination. Different methods include different mechanisms of action of antioxidants, while during extraction of antioxidants, solubility of the antioxidant in reaction media can be a limiting step since there is always an insoluble fraction of material [2]. Gökmen et al. [3] developed a direct procedure called 'QUENCHER' for determination of the antioxidant activity which is useful to assess the antioxidant activity of a given foodstuff without previous extraction, which gives rise to a fast assay that avoids the 
problem related with antioxidant extraction. It has been shown that by QUENCHER method it is possible to evaluate the antioxidant activity of compounds without any extraction when compounds are still bound to the insoluble matrices taking advantage from the surface reaction phenomenon between solid and liquid material, i.e. between bound antioxidant compounds and soluble free radicals [3-5]. The thermodynamic driving force for the simultaneous solubilisation and reaction of antioxidants in the QUENCHER method is the high equilibrium constant for the redox reaction with antioxidant assay reagents coupled to that of physical dissolution of antioxidants from partly insoluble matrices [5]. Tea has been recognised for its health benefits like antioxidative, anticancerous and antibacterial properties, and it is widely consumed [6].

In this study, evaluation of antioxidant activity of the tea leaves was conducted. Antioxidant activity was determined using $\mathrm{ABTS}^{+}$and $\mathrm{DPPH}^{\circ}$ free radicals which were applied on the tea leaf extracts (methanol and acidified methanol extracts) and directly on pulverised tea leaves (QUENCHER method). Results of antioxidant activity of the QUENCHER method and antioxidant activity obtained in extracts were compared to establish if there was difference in antioxidant activity when those two methods were used.

\section{Methods}

\section{Extraction of the tea leaves}

The tea leaves (green, yellow and black) obtained from local market were used for the evaluation. One gram of intact tea leaves or pulverised tea leaves was extracted with $20 \mathrm{~mL}$ of methanol or acidified methanol (methanol: conc. $\mathrm{HCl}=50: 1$ ) for $1 \mathrm{~h}$. After extraction, mixture was filtrated and obtained extracts were recovered and used for determination of total phenolic compounds, total flavonoid and tannin content, as well as antioxidant activity.

\section{Determination of total phenolic compound content}

The total phenolic compound content was determined by the Folin-Ciocalteu method [7]. The results were expressed as g gallic acid equivalent $/ \mathrm{kg}$ of tea leaves ( $\mathrm{g}$ $\mathrm{GAE} / \mathrm{kg}$ ). Measurements were conducted in triplicates.

\section{Determination of total flavonoid content}

The total flavonoid content was determined by a method described by Makris et al. [8]. The flavonoid content was calculated from a calibration curve using a catechin as standard and expressed as $\mathrm{g}$ catechin equivalents $/ \mathrm{kg}$ of tea leaves (g CTE/kg). Measurements were conducted in triplicates.

\section{Determination of tannin content}

The tannin content was determined by a method described by Nakamura et al. [9]. The tannin content was calculated from a calibration curve using a catechin as standard and expressed as g catechin equivalents $/ \mathrm{kg}$ of tea leaves (g CTE/kg). Measurements were conducted in triplicates.

\section{Determination of antioxidant activity of tea leaf extracts}

The antioxidant activity was determined using two methods, ABTS and DPPH methods. The ABTS assay followed the method of Arnao et al. [10] with some modifications. The results were expressed as $\mu \mathrm{mol}$ trolox equivalents (TE)/100 $\mathrm{g}$ of tea leaves ( $\mu$ mol TE/100 g). Additional dilution was needed if the measured ABTS value was over the linear range of the standard curve. For the DPPH assay, $0.2 \mathrm{~mL}$ of the sample was diluted with methanol, and $1 \mathrm{~mL}$ of DPPH solution was added. After $15 \mathrm{~min}$, the absorbance was read at $517 \mathrm{~nm}$. The results were expressed as $\mu \mathrm{mol}$ trolox equivalents (TE)/ $100 \mathrm{~g}$ of tea leaves $(\mu \mathrm{mol} \mathrm{TE} / 100 \mathrm{~g})$. Additional dilution was needed if the measured DPPH value was over the linear range of the standard curve. Measurements were conducted in triplicates.

\section{Determination of antioxidant activity of tea leaves by QUENCHER method}

The antioxidant activity by the QUENCHER method was determined according to Serpen et al. [4] with slight modification. Five milligrams of pulverised tea leaves was mixed with $6 \mathrm{~mL}$ of ABTS or DPPH reagent. Mixture was vortexed for $5 \mathrm{~min}$ to facilitate the surface reaction between the insoluble matters, and then liquid part was separated from crude part. After $15 \mathrm{~min}$, the absorbance of the optically clear supernatant was measured at $734 \mathrm{~nm}$ (ABTS) or $517 \mathrm{~nm}$ (DPPH) using a UV-vis spectrophotometer. The results were expressed as $\mu \mathrm{mol}$ trolox equivalents (TE)/100 g of tea leaves ( $\mu$ mol TE/ $100 \mathrm{~g})$. For comparison of results, the same procedure was conducted with acidified methanol extracts. Measurements were conducted in triplicates.

\section{Statistical analysis}

Obtained results were analysed by the analysis of variance (ANOVA) and Fisher's least significant difference (LSD) with significance defined at $P<0.05$. All statistical analyses were carried out using the software program STATISTICA 8 (StatSoft, Inc, USA). The results were expressed as means \pm standard deviation.

\section{Results and discussion}

The first part of this study was to determine influence of particle size, pulverised and intact leaves, and extraction solvent (methanol and acidified methanol) on phenolics, 
flavonoids, tannins and antioxidant activity of the green, black and yellow tea leaves. Results are presented in Table 1. Total phenolic content (TPC) of yellow, green and black tea leaves was from $0.575 \mathrm{~g} / \mathrm{kg}$ to $6.629 \mathrm{~g} / \mathrm{kg}$, depending on particle size and extraction solvent. The yellow tea leaves had the highest TPC $(2.433 \mathrm{~g} / \mathrm{kg}$ to $6.629 \mathrm{~g} / \mathrm{kg}$ ), regardless of the particle size and the extraction solvent. TPC in methanol extracts decreased in following order yellow $>$ green $>$ black tea leaves and in acidified methanol extracts yellow $>$ black $>$ green tea leaves, regardless of the particle size. Particle size of samples had also an influence on TPC. Pulverised leaves $(1.139 \mathrm{~g} / \mathrm{kg}$ to $6.629 \mathrm{~g} / \mathrm{kg})$ had higher TPC than intact leaves $(0.575 \mathrm{~g} / \mathrm{kg}$ to $5.108 \mathrm{~g} / \mathrm{kg})$, regardless of the extraction solvent. Overall, the highest TPC had acidified methanol extracts of the pulverised yellow tea leaves, and the lowest methanol extracts of the black tea leaves. Total flavonoid content (TFC) was possible to determine only in extracts obtained with methanol as the extraction solvent. Acidified methanol, as the extraction solvent, probably causes the extraction of some compounds which are reacting with the reagents for determination of TFC leading to blurring the sample and disabling its spectrophotometric evaluation. TFC and tannin content (TC) followed the same tendency as TPC. TFC of methanol extracts ranged from $0.220 \mathrm{~g} / \mathrm{kg}$ to $3.776 \mathrm{~g} /$ $\mathrm{kg}$, depending on tea leaves and particle size. TC ranged from $0.168 \mathrm{~g} / \mathrm{kg}$ to $1.948 \mathrm{~g} / \mathrm{kg}$, depending on the tea leaves, extraction solvent and particle size. The highest TFC and TC of methanol extracts were determined in the pulverised yellow tea leaves $(3.776 \mathrm{~g} / \mathrm{kg}$ and $1.045 \mathrm{~g} /$ $\mathrm{kg}$, respectively), while the yellow tea leaf extracts had lower values $(1.679 \mathrm{~g} / \mathrm{kg}$ and $0.658 \mathrm{~g} / \mathrm{kg}$, respectively). TFC and TC of methanol extracts of the pulverised green tea leaves were $1.557 \mathrm{~g} / \mathrm{kg}$ and $0.691 \mathrm{~g} / \mathrm{kg}$ and in the intact green tea leaves were $0.671 \mathrm{~g} / \mathrm{kg}$ and $0.375 \mathrm{~g} /$ $\mathrm{kg}$. Methanol extracts of the black tea had the lowest TFC and TC $(0.326 \mathrm{~g} / \mathrm{kg}$ and $0.263 \mathrm{~g} / \mathrm{kg}$ for pulverised leaves, and $0.220 \mathrm{~g} / \mathrm{kg}$ and $0.168 \mathrm{~g} / \mathrm{kg}$ for intact leaves). Acidified methanol extracts had higher TC than methanol extracts. The highest TC had the pulverised yellow tea leaves $(1.948 \mathrm{~g} / \mathrm{kg})$ and the intact yellow tea leaves $(1.556 \mathrm{~g} / \mathrm{kg})$. Interestingly, the methanol extracts of black tea had lower TPC and TC than methanol extracts of the green tea, while in acidified methanol extracts reverse tendency was observed.

Extraction of phenolic compounds from plant material depends on various factors like phenolic compounds structure, extraction method, particles size, sample storage conditions and presence of other compounds (they can

Table 1 Total phenolics, flavonoids, tannins and antioxidant activity of the green, black and yellow tea leaves

\begin{tabular}{|c|c|c|c|c|c|}
\hline Samples & TPC (g/kg) & TFC $(\mathbf{g} / \mathbf{k g})$ & $\mathrm{TC}(\mathrm{g} / \mathrm{kg})$ & $\mathrm{DPPH}(\mu \mathrm{mol} / 100 \mathrm{~g})$ & ABTS $(\mu \mathrm{mol} / 100 \mathrm{~g})$ \\
\hline \multicolumn{6}{|l|}{ Methanol } \\
\hline \multicolumn{6}{|l|}{ YT } \\
\hline Pulverised & $4.116 \pm 0.113^{a}$ & $3.776 \pm 0.004^{a}$ & $1.045 \pm 0.003^{a}$ & $18.825 \pm 0.094^{a}$ & $29.345 \pm 0.124^{a}$ \\
\hline Intact & $2.433 \pm 0.213^{b}$ & $1.679 \pm 0.037^{b}$ & $0.658 \pm 0.004^{b}$ & $16.846 \pm 0.046^{b}$ & $23.007 \pm 0.283^{b}$ \\
\hline \multicolumn{6}{|l|}{ GT } \\
\hline Pulverised & $2.262 \pm 0.113^{b}$ & $1.557 \pm 0.026^{b}$ & $0.691 \pm 0.001^{c}$ & $16.040 \pm 0.503^{c}$ & $20.738 \pm 0.171^{c}$ \\
\hline Intact & $1.109 \pm 0.149^{c}$ & $0.671 \pm 0.041^{c}$ & $0.375 \pm 0.002^{d}$ & $13.109 \pm 0.125^{d}$ & $16.067 \pm 0.286^{d}$ \\
\hline \multicolumn{6}{|l|}{ BT } \\
\hline Pulverised & $1.139 \pm 0.064^{c}$ & $0.326 \pm 0.017^{d}$ & $0.263 \pm 0.003^{e}$ & $12.241 \pm 0.346^{\mathrm{e}}$ & $16.356 \pm 0.314^{d}$ \\
\hline Intact & $0.575 \pm 0.049^{d}$ & $0.220 \pm 0.022^{e}$ & $0.168 \pm 0.003^{f}$ & $11.930 \pm 0.434^{f}$ & $13.064 \pm 0.132^{e}$ \\
\hline \multicolumn{6}{|l|}{ Methanol $+\mathrm{HCl}$} \\
\hline \multicolumn{6}{|l|}{ YT } \\
\hline Pulverised & $6.629 \pm 0.121^{\mathrm{e}}$ & $x$ & $1.948 \pm 0.001^{9}$ & $26.521 \pm 0.081^{9}$ & $40.733 \pm 0.314^{f}$ \\
\hline Intact & $5.108 \pm 0.135^{f}$ & $x$ & $1.556 \pm 0.002^{h}$ & $21.427 \pm 0.262^{h}$ & $32.237 \pm 0.251^{9}$ \\
\hline \multicolumn{6}{|l|}{ GT } \\
\hline Pulverised & $3.823 \pm 0.142^{9}$ & $x$ & $1.168 \pm 0.003^{i}$ & $20.382 \pm 0.046^{i}$ & $32.815 \pm 0.472^{\mathrm{g}}$ \\
\hline Intact & $3.662 \pm 0.199^{9}$ & $x$ & $1.066 \pm 0.004^{\mathrm{a}}$ & $19.159 \pm 0.162^{j}$ & $27.055 \pm 0.289^{h}$ \\
\hline \multicolumn{6}{|l|}{ BT } \\
\hline Pulverised & $4.226 \pm 0.270^{h}$ & $x$ & $1.256 \pm 0.001^{j}$ & $18.002 \pm 0.062^{k}$ & $27.032 \pm 0.032^{h}$ \\
\hline Intact & $3.733 \pm 0.242^{i}$ & $x$ & $0.941 \pm 0.002^{k}$ & $17.513 \pm 0.088^{\prime}$ & $26.120 \pm 0.075^{i}$ \\
\hline
\end{tabular}

Total phenolics (TPC), flavonoids (TFC), tannins (TC) and antioxidant activity (DPPH and ABTS) of the green (GT), black (BT) and yellow (YT) tea leaves.

Values in the same column with different superscripts (a to k) are significantly different $(P<0.05)$ by analysis of variance (ANOVA) and Fisher's least significant difference (LSD). 
interfere extraction or can be extracted with phenolics). Structure of phenolics varies from simple ones to polymerised, but they can be bonded with carbohydrates, proteins and other compounds of plant material. Some phenolics with high molecular mass and their complexes can be insoluble making their extraction from the plant material very difficult. Considering all above, extracted phenolics of some plant material are the mixture of different types of phenolics, which are soluble in used extraction solvent. For elimination of unwanted phenolics and/or other compounds (like waxes, lipids and terpenes), some additional steps during the extraction can be taken meaning that extraction time will be prolonged and degradation of wanted phenolics could occur $[11,12]$. Solubility of phenolics in extraction solvent depends on polarity of solvent, polymerisation of phenolics and interactions with other compounds. Methanol, ethanol, acetone, water, ethyl acetate or their combinations are commonly used extraction solvents for phenolic compounds [12]. Influence of the particle size on increasing extraction efficiency was also determined in other studies [13-15]. Our results are in accordance with results of Ramadani et al. [16] who also determined that the green tea leaves had significantly higher total phenolic content and tannin content than the black tea leaves. In their case, the green tea leaves had $231 \mathrm{~g} / \mathrm{kg}$ DM of total phenolics and $204 \mathrm{~g} / \mathrm{kg}$ DM of total tannins versus black tea which had $151 \mathrm{~g} / \mathrm{kg}$ DM of total phenolics and $133 \mathrm{~g} / \mathrm{kg}$ DM. In a study of several brands of the green and black tea, it was also determined that generally green tea leaves had higher total phenol content ( 14 to $21 \mathrm{~g} / 100 \mathrm{~g}$ ) than black tea leaves (8 to $17 \mathrm{~g} / 100 \mathrm{~g}$ ) [17].

Antioxidant activity was determined by application of the $\mathrm{DPPH}^{-}$or $\mathrm{ABTS}^{\cdot+}$ free radicals. Regardless of used free radicals, the highest antioxidant activity, as it was expected, had acidified methanol extracts obtained by extraction of pulverised tea leaves. The yellow tea had the highest antioxidant activity $(40.733 \mu \mathrm{mol} / 100 \mathrm{~g}$ and $26.521 \mu \mathrm{mol} / 100 \mathrm{~g}$, determined by $\mathrm{ABTS}^{\cdot+}$ and $\mathrm{DPPH}^{\circ}$ for pulverised tea leaves; and $32.237 \mu \mathrm{mol} / 100 \mathrm{~g}$ and $21.427 \mu \mathrm{mol} / 100 \mathrm{~g}$, determined by ABTS ${ }^{\circ}+$ and $\mathrm{DPPH}^{\circ}$ for intact tea leaves). Green and black tea had lower values (from $26.120 \mu \mathrm{mol} / 100 \mathrm{~g}$ to $32.815 \mu \mathrm{mol} / 100 \mathrm{~g}$ determined by $\mathrm{ABTS}^{\circ}+$, and from $17.513 \mu \mathrm{mol} / 100 \mathrm{~g}$ to $20.382 \mu \mathrm{mol} / 100 \mathrm{~g}$ determined by $\mathrm{DPPH}^{*}$ ). In methanol extracts, the highest antioxidant activity was also determined in the pulverised yellow tea leaves $(29.345 \mu \mathrm{mol} /$ $100 \mathrm{~g}$ and $18.825 \mu \mathrm{mol} / 100 \mathrm{~g}$ determined by ABTS ${ }^{\circ}+$ and $\mathrm{DPPH}^{\circ}$ ). Comparing results of antioxidant activity obtained by both methods, it can be seen that the results of application of ABTS ${ }^{++}$are higher than the results of $\mathrm{DPPH}^{\circ}$ free radicals. Antioxidant activity of phenolic compounds depends on a number of $\mathrm{OH}$-groups and their position [18]. OH-groups on $3^{\prime}-, 4^{\prime}-, 5^{\prime}$ - position of B-ring of flavonoids increase the antioxidant activity of the compounds in contrast to the phenolics with one hydroxy group $[19,20]$. Different free radicals were used for the determination of the antioxidant activity causing different reactivity with the phenolic compounds depending on their structure [21]. The $\mathrm{ABTS}^{\cdot+}$ has low selectivity in reactions with $\mathrm{H}$-atom donors since it is reacting with any hydroxylated aromatics independently on their real antioxidant potential [22-24]. In contrast to $\mathrm{ABTS}^{\cdot+}$, the DPPH does not react with flavonoids, which contain no $\mathrm{OH}$-groups in B-ring as well as with aromatic acids containing only one OH-group [24,25].

The second part of this study was to compare antioxidant activity determined by different methods, QUENCHER method and extraction method, using the $\mathrm{DPPH}^{-}$and $\mathrm{ABTS}^{++}$free radicals. For comparison, acidified methanol extracts of pulverised tea leaves were used. Using the QUENCHER method, which is based on the direct application of the free radicals on sample, influence of the extraction solvent on antioxidant compounds in sample and their possible degradation are avoided.

Comparing results (Table 2), obtained by the QUENCHER method and the results from extracts, it can be seen that the yellow tea and the green tea had higher antioxidant activity obtained by the direct application of free radicals, while for the black tea, higher antioxidant activity was obtained when the extraction was used prior determination of the antioxidant activity. Evaluating extracts, higher antioxidant activity was obtained by application of the ABTS ${ }^{++}$ free radicals. Results of the QUENCHER method had a different tendency. Only antioxidant activity of the black tea was higher when the ABTS ${ }^{+}$free radicals were used, while the green tea had almost the same values, and the yellow tea leaves had higher antioxidant activity when the $\mathrm{DPPH}^{\circ}$ free radicals were used. Pastoriza et al. [26]

Table 2 Antioxidant activity of the pulverised leaves and extracts of the yellow, green and black tea leaves

\begin{tabular}{lll}
\hline Samples & DPPH $(\boldsymbol{\mu m o l} / \mathbf{1 0 0} \mathbf{g})$ & ABTS $(\boldsymbol{\mu m o l} / 100 \mathrm{~g})$ \\
\hline YT & & \\
$\quad$ Pulverised leaves & $1.994 \pm 0.068^{\mathrm{a}}$ & $1.769 \pm 0.032^{\mathrm{a}}$ \\
$\quad$ Extract & $0.626 \pm 0.068^{\mathrm{b}}$ & $0.871 \pm 0.050^{\mathrm{b}}$ \\
GT & & \\
$\quad$ Pulverised leaves & $0.753 \pm 0.096^{\mathrm{b}}$ & $0.744 \pm 0.062^{\mathrm{b}, \mathrm{c}}$ \\
$\quad$ Extract & $0.388 \pm 0.031^{\mathrm{c}}$ & $0.649 \pm 0.017^{\mathrm{c}, \mathrm{d}}$ \\
BT & & \\
$\quad$ Pulverised leaves & $0.171 \pm 0.009^{\mathrm{d}}$ & $0.335 \pm 0.070^{\mathrm{e}}$ \\
$\quad$ Extract & $0.347 \pm 0.017^{\mathrm{c}}$ & $0.570 \pm 0.040^{\mathrm{d}}$ \\
\hline
\end{tabular}

Antioxidant activity of the pulverised leaves and extracts of the yellow (YT), green (GT) and black (BT) tea leaves.

Values in the same column with different superscripts (a to d) are significantly different $(P<0.05)$ by analysis of variance (ANOVA) and Fisher's least significant difference (LSD). 
evaluated antioxidant activity in different foods using the $\mathrm{ABTS}^{++}$free radicals and obtained higher antioxidant values for the most evaluated foods when the QUENCHER method was used in comparison to the extracts. Some exceptions (like fresh carrots, apples, potato chips, boiled ham and salami-type sausage) were noted, and in those samples, higher antioxidant activity was evaluated in extracts. Delgado-Andrade et al. [27] also determined much higher antioxidant activity in the wheat bread and the wheat bran bread by the QUENCHER method for $\mathrm{ABTS}^{\cdot+}$ and $\mathrm{DPPH}^{\cdot}$ free radicals than in extracts. Also, they determined that values obtained by the $\mathrm{ABTS}^{\cdot+}$ were higher than with the $\mathrm{DPPH}^{*}$ free radicals. In some cases (like lentil, strawberry, apples, almond, pistachio nut, hazelnut or insoluble fractions of lettuce, orange, lemon, cocoa, biscuits, snacks and bread crust), antioxidant activity determined by the $\mathrm{DPPH}^{\circ}$ was similar or higher than with the $\mathrm{ABTS}^{\circ}$, when the QUENCHER method was used $[4,5]$. The $\mathrm{DPPH}^{*}$ has higher solubility in less polar solvents; thus, more reactivity towards lipidrich containing structures can be expected. The lipid globules in samples could not act as a molecular barrier for $\mathrm{DPPH}^{\cdot}$ that can reach both the lipophilic and hydrophilic antioxidant compounds presented in the core of the solid particles. The diffusivity phenomenon could be one of the primary explanations for the higher antioxidant activity when using the $\mathrm{DPPH}^{*}$ compared to the $\mathrm{ABTS}^{\cdot+}$ [5].

\section{Conclusions}

The particle size and the extraction solvent had high influence on the total phenolic compounds, total flavonoid and tannin content as well as on the antioxidant activity. When the extraction was conducted on pulverised tea leaves with acidified methanol, higher values of mentioned parameters were obtained.

The yellow tea leavse had the highest values of evaluated parameters, compared to those of the green tea and the black tea leaves. Comparing the results of antioxidant activity, obtained in the extracts and by the QUENCHER method, the yellow and the green tea leaves had higher antioxidant activity obtained by the QUENCHER method than in extracts, while the black tea leaves had higher antioxidant activity when the extraction was used prior determination of antioxidant activity.

\section{Competing interests}

The authors declare that they have no competing interests.

\section{Authors' contributions}

MK made the conception and design for experiment. MK and VP conducted the final details around experimental part and did the final reading and corrections. MT (Kopjars student) was involved in conducting experimental part under MK's supervision and with MK's help. All authors were involved in interpretation of results and discussion about it. MK wrote the first draft of manuscript with MT's help. In my opinion, all of us gave sufficient contribution to the experimental part and writing manuscript, and we can be co-authors of this manuscript. All authors read and approved the final manuscript.

\section{Acknowledgements}

This research was supported by National Scientific Project financed by Croatian Ministry of Science, Education and Sports.

Received: 25 September 2014 Accepted: 15 December 2014

Published online: 27 January 2015

\section{References}

1. Pellegrini N, Serafini M, Colombi B, Del Río D, Salvatore S, Bianchi M, Brighenti F (2003) Total antioxidant capacity of plant foods, beverages, and oils consumed in Italy assessed by three different in vitro assays. J Nutr 133(9):2812-2819

2. Pérez-Jiménez J, Arranz S, Tabernero M, Diaz-Rubio ME, Serrano J, Gońi I, Saura-Calixto F (2008) Update methodology to determine antioxidant capacity in plant foods, oils and beverages: extraction, measurement and expression of results. Food Res Int 41(3):274-285

3. Gökmen V, Serpen A, Fogliano V (2009) Direct measurement of the total antioxidant capacity of foods: the 'QUENCHER'approach. Trends Food Sci Technol 20(6-7):278-288

4. Serpen A, Capuano E, Fogliano V, Gökmen V (2007) A new procedure to measure the antioxidant activity of insoluble food components. J Agric Food Chem 55(19):7676-7681

5. Serpen A, Gökmen V, Fogliano V (2012) Solvent effects on total antioxidant capacity of foods measured by direct QUENCHER procedure. J Food Compos Anal 26(1-2):52-57

6. Borse BB, Kumar HV, Rao LJM (2007) Radical scavenging conserves from unused fresh green tea leaves. J Agric Food Chem 55(5):1750-1754

7. Ough CS, Amarine MA (1998) Phenolic compounds. In: Methods for analysis of musts and wines. John Wiley \& Sons, Inc., New York

8. Makris DP, Boskou G, Andrikopoulo NK (2007) Polyphenolic content and in vitro antioxidant characteristics of wine industry and other agri-food solid waste extracts. J Food Compos Anal 20(2):125-132

9. Nakamura Y, Tsui S, Tonogai Y (2003) Analysis of proanthocyanidins in grape seed extracts, health foods, and grape seed oils. J Health Sci 49(1):45-54

10. Arnao MB, Cano A, Acosta M (2001) The hydrophilic and lipophilic contribution to total antioxidant activity. Food Chem 73(2):239-244

11. Robbins R (2003) Phenolic acids in foods: an overview of analytical methodology. J Agric Food Chem 51(10):2866-2887

12. Naczk M, Shahidi F (2004) Extraction and analysis of phenolics in food. J Chromatogr A 1054(1-2):95-111

13. Bucić-Kojić A, Planinić M, Tomas S, Bilić M, Velić D (2007) Study of solid-liquid extraction kinetics of total polyphenols from grape seeds. J Food Eng 81(1):236-242

14. Franco D, Pinelo M, Sineiro J, Nunez MJ (2007) Processing of Rosa rubiginosa: extraction of oil and antioxidant substances. Bioresour Technol 98(18):3506-3512

15. Gião MS, Pereira Cl, Fonesca SC, Pintado ME, Malcata FX (2009) Effects of particle size upon the extent of extraction of antioxidant power from plants agrimonia eupatoria, salvia sp and Satureja Montana. Food Chem 117(3):412-416

16. Ramdani D, Chaudhry AS, Seal CJ (2013) Chemical composition, plant secondary metabolites, and minerals of green and black teas and the effect of different Tea-to-water ratios during their extraction on the composition of their spent leaves as potential additives for ruminants. J Agric Food Chem 61(20):4961-4967

17. Anesini C, Ferraro GE, Filip R (2008) Total polyphenol content and antioxidant capacity of commercially available Tea (camellia sinensis) in Argentina. J Agric Food Chem 56(19):9225-9229

18. Kazazić SP (2004) The antioxidant and antiradical activity of flavonoids (in Croatian). Arhiva Higijene Rada Toksikologije 55:279-290

19. Rice-Evans CA, Miller NY, Bolwell PG, Bramley PM, Pridham JB (1995) The relative antioxidant activities of plant-derived polyphenolic flavonoids. Free Rad Res 22(4):375-382

20. Heim KE, Tagliaferro AR, Bobilya DJ (2002) Flavonoid antioxidants: chemistry, metabolism and structure-activity relationship. J Nutr Biochem 13(10):572-584 
21. Singleton VL, Rossi JA (1965) Colorimetry of total phenolics with phosphmolibdic-phosphotonutric acid reagents. Am J Enol Vitic 16(3):144-158

22. Campos AM, Lissi EA (1997) Kinetics of the reaction between 2,2'-azibobis(3ethylbenzozolin-6-sulfonic acid) (ABTS) derived radical cation and phenols. Int J Chem Kinet 29(3):219-224

23. Arts MJTJ, Dallinga JS, Voss HP, Haenen GRMM, Bast A (2003) A critical appraisal of the use of antioxidant capacity (TEAC) assay in defining optimal antioxidant structures. Food Chem 80(3):409-414

24. Roginsky V, Lissi EA (2005) Review of methods to determine chain-breaking antioxidant activity in food. Food Chem 92(2):235-254

25. Yokozawa T, Chen P, Dong E, Tanaka T, Nonaka Gl, Nishioka I (1998) Study on the inhibitory effects of tannins and flavonoids against 1,1-diphenyl-2picrylhydrazyl radical. Biochem Pharm 56(2):213-222

26. Pastoriza S, Delgado-Andrade C, Haro A, Rufián-Henares JA (2011) A physiologic approach to test the global antioxidant response of foods. The GAR method. Food Chem 129(4):1926-1932

27. Delgado-Andrade C, Conde-Aguilera JA, Haro A, Pastoriza S, Rufián-Henares JA (2010) A combined procedure to evaluate the global antioxidant response of bread. J Cereal Sci 52(2):239-246

\section{Submit your manuscript to a SpringerOpen ${ }^{\circ}$ journal and benefit from:}

- Convenient online submission

- Rigorous peer review

- Immediate publication on acceptance

- Open access: articles freely available online

- High visibility within the field

- Retaining the copyright to your article 